\title{
Currents and Voltages Induced by Electric Field in Two Converging Single-wire Overhead Transmission Lines
}

\author{
Kirill Zimin ${ }^{1}$, Nina Rubtsova $^{2}$, Andrey Tokarskskiy ${ }^{1}$ \\ ${ }^{1}$ Joint-Stock Company "Research and Development Center of the Federal Grid Company of Unified Energy System", Kashirskoe \\ shosse, 22, bld.3, Moscow, Russia \\ ${ }^{2}$ Federal State Budgetary Scientific Institution “Izmerov Research Institute of Occupational Health”, prospect Budennogo,31, \\ Moscow, Russia
}

\begin{abstract}
The calculations of induced by electric field voltage and current for $i$ line grounded and ungrounded ends depending on $p$ - line convergence part length, $a_{0}$ minimal distance between convergence lines, and $\Theta$ - the angle of lines convergence. Limit values of $p, a_{0}$ and $\Theta$ are determined, one of which disturbance allows to neglect the electric effect of converging transmission lines.
\end{abstract}

\section{Introduction}

Personnel working on overhead transmission lines (OTL) under induced voltage health maintenance requires these voltages limit values compliance. These requirements compliance ensure is possible by use the developed algorithms for calculation the current and voltage distribution along the disconnected grounded single-wire (single-phase) $i$ line, induced by electric field (EF) of operating single-wire (single-phase) $k$ line, converging with the $i$ line under $\Theta$ angle.

\section{Partial capacitance between convergent single-wire $i$ and $k$ lines}

Consider first two parallel single-wire $i$ and $k$ OTLs located from each other at $a$ distance and at $h_{i}=h$ and $h_{k}=H$ height above the ground (Figure 1, 1a). Figure $1 \mathrm{~b}$ shows the scheme of $i$ and $k$ single-wire OTLs connection between lines and with the ground by partial capacities.

$C_{\mathrm{ii} 0}, C_{\mathrm{kk} 0}$ и $C_{\mathrm{ki} 0}$ specific partial capacities are determined by Maxwell's formulas first group potential factors use (1).

$$
\left.\begin{array}{l}
\alpha_{11}=\alpha_{k k}=\frac{1}{2 \pi \varepsilon_{0}} \ln \frac{2 H}{R}, \quad \alpha_{22}=\alpha_{i i}=\frac{1}{2 \pi \varepsilon_{0}} \ln \frac{2 h}{r}, \\
\alpha_{12}=\alpha_{21}=\alpha_{k i}=\alpha_{i k}=\frac{1}{2 \pi \varepsilon_{0}} \ln \frac{\sqrt{a^{2}+(H+h)^{2}}}{\sqrt{a^{2}+(H-h)^{2}}},
\end{array}\right\}
$$

where: $H$ and $h$ are the heights above the ground; $R$ and $r$ are $k$ and $i$ line wires radiuses, respectively.
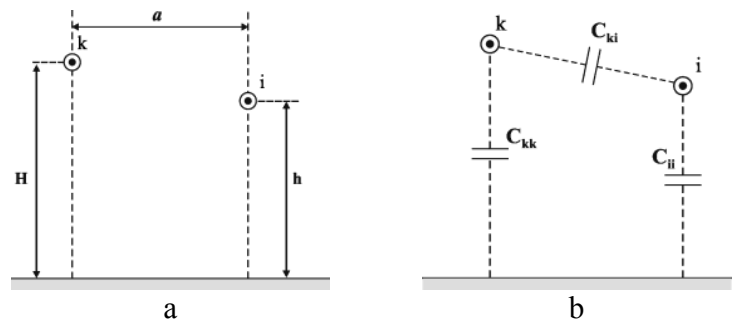

Fig. 1. I and $k$ single-wire OTLs layout (a) and connection between lines and with the ground by partial capacities (b)

Potential factors $\alpha$ matrix has the form (2):

$$
\alpha=\left[\begin{array}{ll}
\alpha_{11} & \alpha_{12} \\
\alpha_{21} & \alpha_{22}
\end{array}\right] .
$$

Matrix $\alpha$ inversion leads to obtain the Maxwell's formulas second group potential factors $\beta$ matrix (3):

$$
\beta=\left[\begin{array}{ll}
\beta_{11} & \beta_{12} \\
\beta_{21} & \beta_{22}
\end{array}\right]=\left[\begin{array}{ll}
\alpha_{11} & \alpha_{12} \\
\alpha_{21} & \alpha_{22}
\end{array}\right]^{-1}=\alpha^{-1} .
$$

Potential factors have dimension is meter per farad $[\mathrm{m} / \mathrm{F}]$, and capacity factors dimension is farad per meter $[\mathrm{F} / \mathrm{m}]$.

Consider lines $k$ and $i$, converging at $\Theta$ angle (Figure 2).

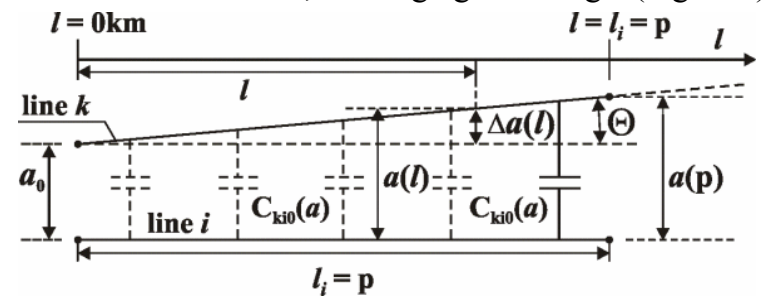

Fig. 2. OTLs $k$ and $i$, converging at $\Theta$ angle

We know: $i$ line length $l_{i}=\mathrm{p}$, the distance between $k$ and $i$ lines at the beginning $a_{0}$ and at the end $a(\mathrm{p})$ of $i$ 
line, and so at the and $a(\mathrm{p})$ of line we know $k$ и $i \Theta$ converging angle, because:

$$
\Theta=\operatorname{arctg}\left(\frac{a(p)-a_{0}}{p}\right)=\operatorname{arctg} \frac{\Delta a(p)}{p} .
$$

Let's count, that $a_{0}=5 \mathrm{~m}$ and $a(\mathrm{p})=100 \mathrm{~m}$. Lines $k$ and $i$ parameters are: $H=19 \mathrm{~m}, h=17.5 \mathrm{~m}, R=r=$ $0.014 \mathrm{~m}$. Partial capacity values between $k$ and $i$ lines are determined by the expression $[1,2] C_{\mathrm{ki} 0}=-\beta_{\mathrm{ki}}=-\beta_{12}$ $=-\beta_{21}$, then on expressions $(1) \div(3)$ we obtain $C_{\mathrm{ki0}}(a)$ values with $a$ change from $5 \mathrm{~m}$ to $100 \mathrm{~m}$ in $5 \mathrm{~m}$ increments, as it is shown in table 1 .

It should be noted that to obtain the values of partial capacities between phases and lighting wires of converging working and disconnected three- or morephase power lines, $C_{\text {kio }}(a)$ value calculation must be carried out taking into account all of these OTL phases and lighting wires. $C_{\text {ki0 }}(a)$ values can be calculated for case from one to six three-phase OTL by computer program “OTL EMF” [3].

Table 1. Capacity $C_{\text {kio }}(a)$ values depending on the distance $a$, obtained by the expressions $(1) \div(3)$

\begin{tabular}{|c|c|c|c|c|c|c|c|}
\hline $\begin{array}{c}a, \\
\mathrm{~m}\end{array}$ & $\begin{array}{c}C_{\text {kio }}(a), \\
\times 10^{-12} \\
\mathrm{~F} / \mathrm{m}\end{array}$ & $\begin{array}{c}a, \\
\mathrm{~m}\end{array}$ & $\begin{array}{c}C_{\text {kio }}(a), \\
\times 10^{-12} \\
\mathrm{~F} / \mathrm{m}\end{array}$ & $\begin{array}{c}a, \\
\mathrm{~m}\end{array}$ & $\begin{array}{c}C_{\text {kio }}(a), \\
\times 10^{-12} \\
\mathrm{~F} / \mathrm{M}\end{array}$ & $\begin{array}{c}a, \\
\mathrm{~m}\end{array}$ & $\begin{array}{c}C_{\text {kio }}(a), \\
\times 10^{-12} \\
\mathrm{~F} / \mathrm{m}\end{array}$ \\
\hline 5 & 1.8704 & 30 & 0.4081 & 55 & 0.1636 & 80 & 0.08477 \\
\hline 10 & 1.2197 & 35 & 0.3304 & 60 & 0.1412 & 85 & 0.07386 \\
\hline 15 & 0.8774 & 40 & 0.2718 & 65 & 0.1229 & 90 & 0.06826 \\
\hline 20 & 0.6614 & 45 & 0.2258 & 70 & 0.1078 & 95 & 0.06172 \\
\hline 25 & 0.5137 & 50 & 0.1916 & 75 & 0.09529 & 100 & 0.05606 \\
\hline
\end{tabular}

To represent $C_{\mathrm{ki0}}(a)$ capacity value changes from $a$ distance in the graphical form, fill in the MathCAD the matrix named $\mathrm{Z}$, containing one row and $\mathrm{c}=20$ columns, $C_{\text {ki0 }}$ values from the table. 1 . Next, we transform it into column matrix and, choosing the boundaries and the step of $\psi_{\mathrm{j}}$ argument changing we obtain $Z_{\mathrm{j}}$ curve with $C_{\mathrm{ki} 0}$ values linear interpolation. To smooth $Z_{j}$ curve, create $\mathrm{ZZ}(\mathrm{y})$ function and set the limits and the step of argument $a$ changing (4):

$$
\left.\begin{array}{l}
\text { ORIGIN }:=1 \quad Z:=\left(\begin{array}{lllll}
1.8704 & 1.2197 & \ldots \ldots & 0.06172 & 0.05606
\end{array}\right) \\
Z:=Z^{T} \cdot 10^{-12} \quad c:=20 \quad \psi_{j}:=j \cdot 5 \\
Z Z(a):=\operatorname{interp}(\operatorname{cspline}(\psi, \mathrm{Z}), \psi, \mathrm{Z}, a) \quad a:=5,5.1 . .100
\end{array}\right\}
$$

ZZ(a) function allows carrying out numerical mathematical operations with it, but it is not analytically determined. Define an analytical expression for $C_{\mathrm{kio}}(a)$ capacity value.

For this purpose, in MathCAD, using the expressions (1) and (2) at $\varepsilon_{0} \equiv \varepsilon$, we carry out the operation of matrix $\alpha$ analytical inversion analytical equal sign $(\rightarrow)$ using:

$$
\begin{gathered}
\alpha^{-1} \rightarrow \frac{-2 \pi \varepsilon}{\ln \left[\frac{\sqrt{a^{2}+H^{2}+2 H h+h^{2}}}{\sqrt{a^{2}+H^{2}-2 H h+h^{2}}}\right]^{2}-\ln \frac{2 H}{R} \cdot \ln \frac{2 h}{r}} \times \\
\times\left[\begin{array}{cc}
\ln \frac{2 h}{r} & \left.-\ln \left[\frac{\sqrt{a^{2}+H^{2}+2 H h+h^{2}}}{\sqrt{a^{2}+H^{2}-2 H h+h^{2}}}\right]\right] . \\
-\ln \left[\frac{\sqrt{a^{2}+H^{2}+2 H h+h^{2}}}{\sqrt{a^{2}+H^{2}-2 H h+h^{2}}}\right] & \ln \frac{2 H}{R}
\end{array}\right] .
\end{gathered}
$$

Then analytically obtained $C_{k i 0}^{A n}(a)$ capacity value can be written (5):

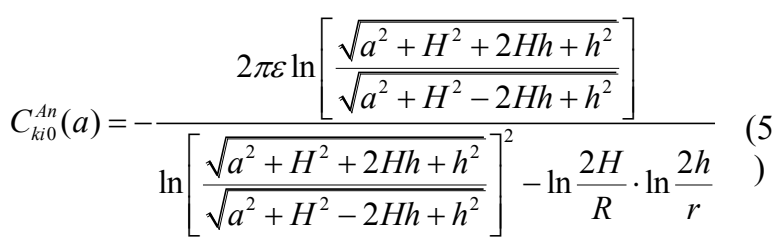

$C_{k i 0}^{A n}(a)$ function disadvantage is complexity, and complexity degree increases dramatically with increasing number of converging lines.

Will hold a rough interpolation (approximation) $\mathrm{ZZ}($ a) curve function (6) using:

$$
C_{k i 0}^{I n t}(a)=d \cdot e^{b \cdot(a-5)}+\frac{d}{1-v \cdot(a-5)}
$$

Let us take follows values of $d, b$ and $v$ indexes: $d=\mathrm{ZZ}(a=5) / 2=0.935 \cdot 10^{-12}, b=-0.6$ и $v=-0.15$. Figure $3 \mathrm{a}$ shows $\mathrm{ZZ}(a)$ and $C_{k i 0}^{A n}(a)$ functions distribution curves, and Figure $3 b$ shows $Z Z(a)$ and $C_{k i 0}^{I n t}(a)$ distribution under $a$ change from от $5 \mathrm{~m}$ to $100 \mathrm{~m}$.

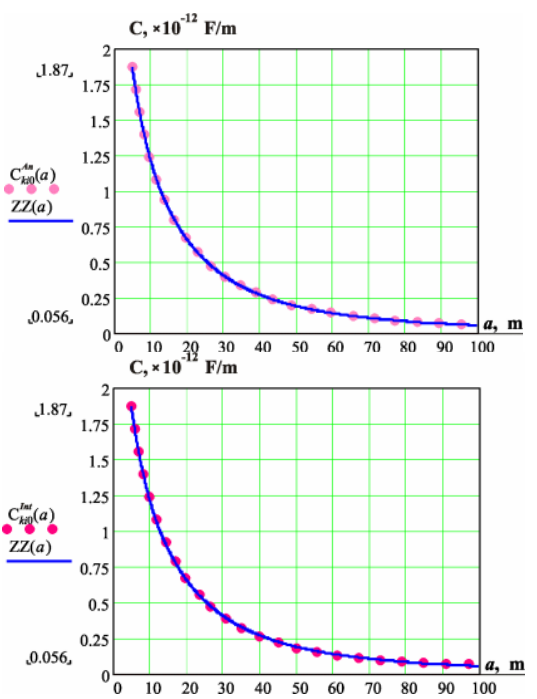

Fig. 3. $Z Z(a)$ and $C_{k i 0}^{A n}(a)$ functions change curves (a), as well as $\mathrm{ZZ}(a)$ and $C_{k i 0}^{\text {Int }}(a)(\mathrm{b})$

The coincidence of $\mathrm{ZZ}(a), C_{k i 0}^{A n}(a)$ and $C_{k i 0}^{I n t}(a)$ curves is good. 
Thus, when calculating transverse voltage induced on the disconnected and grounded single-wire $i$ line by converging single-wire $k$ line electric field, partial capacity between these lines, depending on the distance between them, can be described by $C_{k i 0}(a)=\mathrm{ZZ}(a)$, $C_{k i 0}^{A n}(a)$ and $C_{k i 0}^{I n t}(a)$ functions.

\section{Currents and voltages distribution along grounded at one end $i$ line converging to $k$ line}

OTL $k \quad l_{k}$ length is in idle mode under voltage $\dot{U}_{k}=\dot{E}_{k}=127 \mathrm{kV}$, and $i$ line $l_{i}<l_{k}$ length is disconnected and grounded at one end remoted from $k$ line substation (in this case, the left end) (Figure 4).

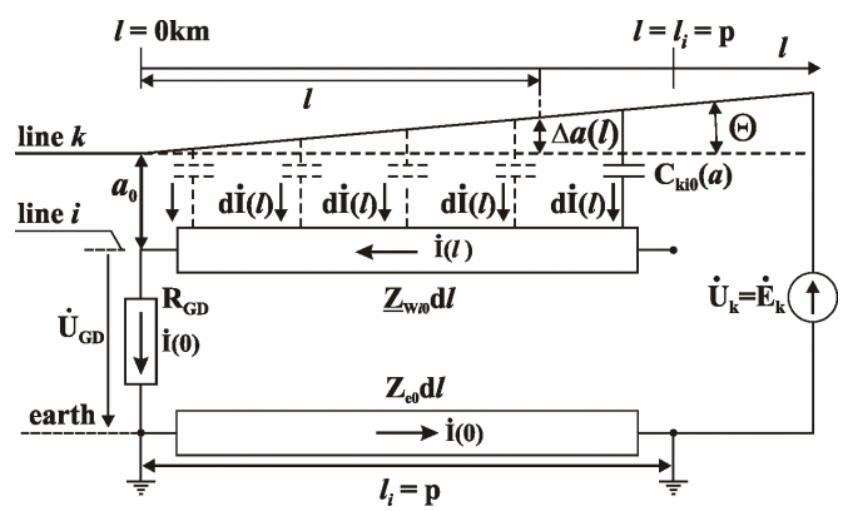

Fig. 4. OTLs converging at $\Theta$ angle: operating $k$ line and $i$ line disconnected and grounded at one end remoted from substation

Descriptions in Figure 4:

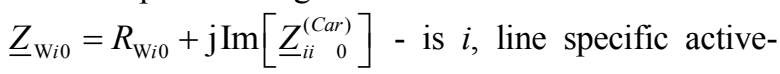
inductive resistance $(\mathrm{Ohm} / \mathrm{km}) ; \quad Z_{\mathrm{e} 0}=\operatorname{Re}\left[\underline{Z}_{i i}^{(\mathrm{Car})}\right]$ - is earth resistivity $(\mathrm{Ohm} / \mathrm{km}) ; R_{\mathrm{GD}}$ - is grounding device (GD) resistance $(\mathrm{Ohm}) ; \underline{Z}_{i i}^{(\mathrm{Car})} 0$ - is own $i$ line wire specific inductive resistance by Carson $(\mathrm{Ohm} / \mathrm{km})$ [4-6]:

$\underline{Z}_{i i \quad}^{(C a r)}=\frac{j \omega \mu_{0} 10^{3}}{2 \pi}\left(\ln \frac{\sqrt{2} \delta_{e}}{r_{W i}}-j \frac{\pi}{4}+\frac{4}{3} \frac{h_{\mathrm{W} i}}{\delta_{e}}(1+j)-0,0772\right)$.

Where: $\omega=2 \pi f$ - angular frequency, $f=50 \mathrm{~Hz} ; \mu_{0}=$ $4 \pi \cdot 10^{-7} \mathrm{H} / \mathrm{m}$ - permeability of vacuum; $r_{\mathrm{W} i}-i$ line wire radius, $\mathrm{m} ; \delta_{e}=\sqrt{2 \rho_{e} / \omega \mu_{0}}$ - penetration depth, $\mathrm{m} ; \rho_{3}$ - earth resistivity, Ohm.m; $h_{\mathrm{W} i}-i$ wire height above the earth. For case $\rho_{\mathrm{e}}=100 \mathrm{Ohm} \cdot \mathrm{m} \quad \underline{Z}_{i i}^{(\mathrm{Car})}=$ $0.0473+\mathrm{j} 0.716 \mathrm{Ohm} / \mathrm{km}$, wire resistivity $R_{\mathrm{W} i 0}=0.074$ $\mathrm{Ohm} / \mathrm{km}, R_{\mathrm{GD}}=10 \mathrm{Ohm}$.

The distance $a(l)$ between $k$ and $i$ OTLs change (Figures 2 and 5) is described by the expression (7):

$$
a(l)=a_{0}+\Delta a(l)=a_{0}+l \cdot \operatorname{tg} \Theta .
$$

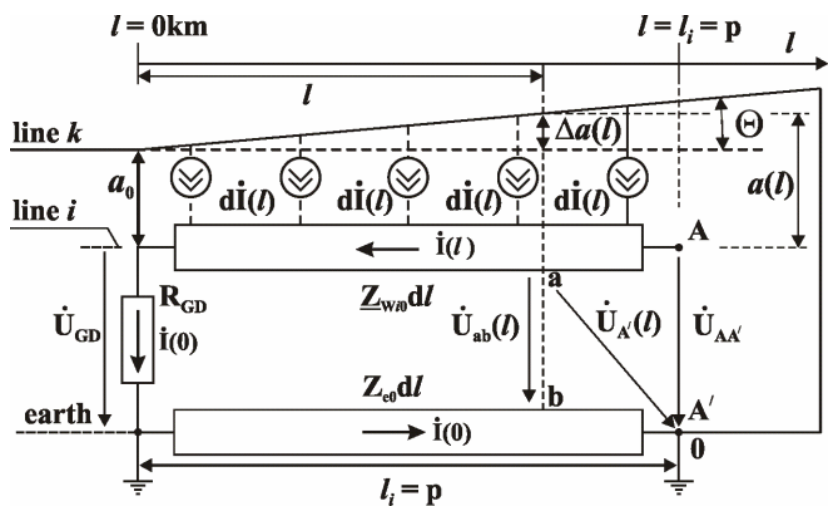

Fig. 5. Scheme of $k$ and $i$ OTLs converging at $\Theta$ angle with electromotive force and specific capacitance replacement at elementary current source

Substituting in $C_{k i 0}(a)$ expression as well as expressions (4) $\div(6)$ instead of variable $a \quad a(l)$ function, get the equations for $C_{k i 0}(l)=\mathrm{ZZ}(a(l)), C_{k i 0}^{A n}(l)$ and $C_{k i 0}^{\text {Int }}(l)$.

Let us replace electromotive force $\dot{E}_{k}$ and specific capacitance $j \omega C_{k i 0}(l) d l$ with elementary current source $d \dot{I}(l)$ (Figure 5): $d \dot{I}(l)=j \omega C_{k i 0}(l) \dot{E}_{k} d l$.

Because $d \dot{I}(l)=j \omega C_{k i 0}(l) \dot{E}_{k} d l$, the current in $i$ line find by expressions in graphic, analytical and interpolation forms:

$$
\begin{aligned}
& \dot{I}(l)=\int_{l}^{l_{i}=p} d \dot{I}(l)=j \omega \dot{E}_{k} \int_{l}^{l_{i}=p} Z Z(a(l)) d l= \\
& =j \omega \dot{E}_{k} \int_{l}^{l_{i}=p} C(l)_{k i 0}^{A n} d l=j \omega \dot{E}_{k} \int_{l}^{l_{i}=p} C(l)_{k i 0}^{I n t} d l
\end{aligned}
$$

Voltage $\dot{U}_{\mathrm{A}^{\prime}}(l)$ value to point $\mathrm{A}^{\prime}$, which potential is assumed to be 0 , and voltage $\dot{U}_{\mathrm{ab}}(l)$ value along $i$ line find by equations:

$$
\begin{aligned}
& \dot{U}_{\mathrm{A}^{\prime}}(l)=\dot{I}(0)\left(R_{\mathrm{GD}}+Z_{30} \mathrm{p}\right)+\underline{Z}_{\mathrm{W} i 0} \int_{0}^{l} \dot{I}(l) d l, \\
& \dot{U}_{\mathrm{ab}}(l)=\dot{I}(0)\left(R_{\mathrm{GD}}+Z_{30} l\right)+\underline{Z}_{\mathrm{W}_{i 0}} \int_{0}^{l} \dot{I}(l) d l .
\end{aligned}
$$

Figure 6 shows current module $\dot{I}(l)$ distribution along $i$ line length $l_{i}=\mathrm{p}=100 \mathrm{~km}$, calculated of capacities: $Z Z(a(l)), C(l)_{k i 0}^{I n t}$ and $C(l)_{k i 0}^{A n}$ at $a_{0}=5$ $\mathrm{m}, \Delta a(\mathrm{p})=100 \mathrm{~m}$ and angle $\Theta=0.0573^{\circ}(\mathrm{a})$, and of parallel $i$ and $k$ lines at $a_{0}=5 \mathrm{~m}, \Delta a(\mathrm{p})=0 \mathrm{~m}$ and angle $\Theta=0^{\circ}(\mathrm{b})$.

Angle $\Theta$ of lines converging increase from $0^{\circ}$ to $0.0573^{\circ}$ leads to current at line $i$ grounded end decreased by 5.7 from $7.46 \mathrm{~A}$ to $1.31 \mathrm{~A}$. 

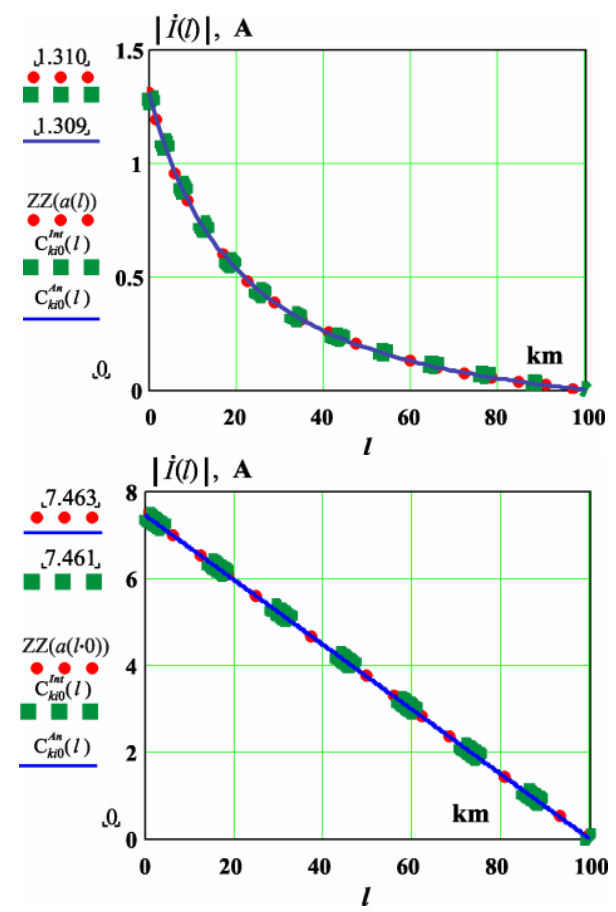

Fig. 6. Current module $\dot{I}(l)$ distribution of $Z Z(a(l))$, $C(l)_{k i 0}^{I n t}$ and $C(l)_{k i 0}^{A n}$ at $\mathrm{p}=100 \mathrm{~km}, a_{0}=5 \mathrm{~m}, \Delta a(\mathrm{p})=100 \mathrm{~m}$ : (a) converging $k$ and $i$ lines; (b) at $\mathrm{p}=100 \mathrm{~km}, a_{0}=5 \mathrm{~m}, \Delta a(\mathrm{p})=$ $0 \mathrm{~m}$ parallel $k$ and $i$ lines

Figure 7 shows the distribution of voltages $\dot{U}_{\mathrm{A}^{\prime}}(l)$ and $\dot{U}_{\mathrm{ab}}(l)$ modules (a) and arguments (b) of $Z Z(a(l)), C(l)_{k i 0}^{I n t}$ and $C(l)_{k i 0}^{A n}$ at $a_{0}=5 \mathrm{~m}, \Delta a(\mathrm{p})=$ $100 \mathrm{~m}, \mathrm{p}=100 \mathrm{~km}$.
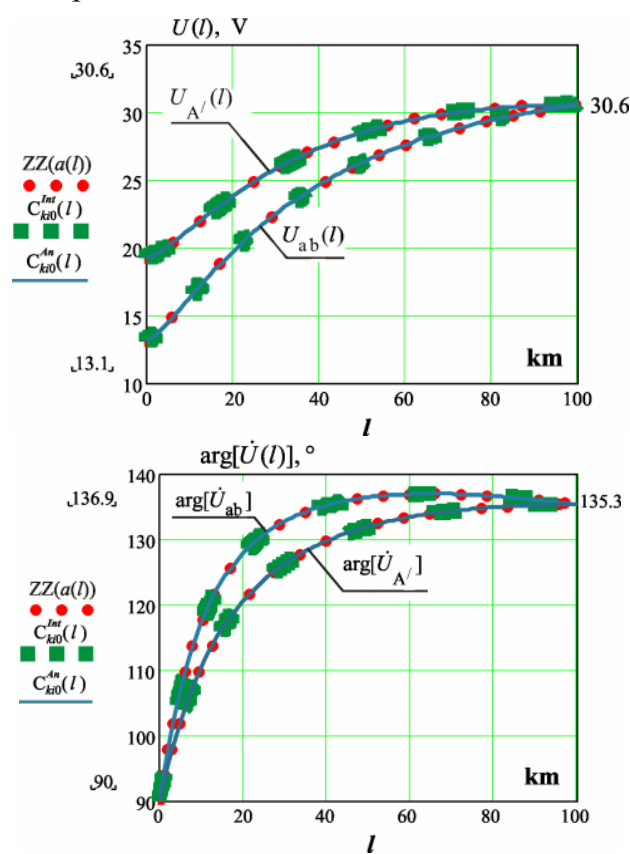

Fig. 7. $\dot{U}_{\mathrm{A}^{\prime}}(l)$ and $\dot{U}_{\mathrm{ab}}(l)$ voltages modules (a) and arguments (b) distribution for $Z Z(a(l)), C(l)_{k i 0}^{\operatorname{Int}}$ uand $C(l)_{k i 0}^{A n}$ under $a_{0}=5 \mathrm{~m}, \Delta a(\mathrm{p})=100 \mathrm{~m}, \mathrm{p}=100 \mathrm{~km}$

Consider the case of $i$ line grounded at near to $k$ line right end (Figure 8).

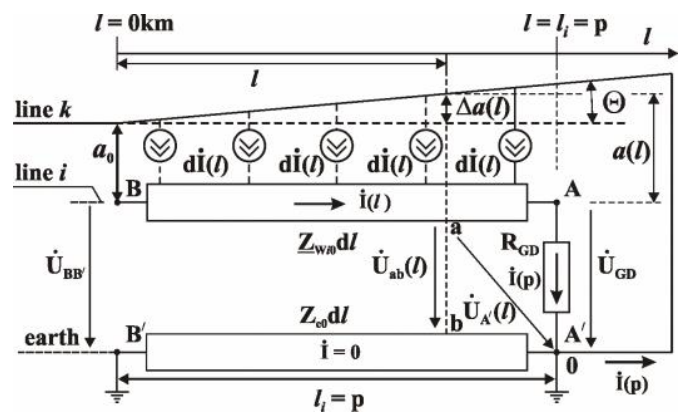

Fig. 8. The scheme of converging at $\Theta$ angle $k$ and $i$ OTLs with $i$ line grounded at right end

$\dot{I}(l)$ current in graphic, analytical and interpolation forms are presented in (8):

$$
\left.\begin{array}{l}
\dot{I}(l)=\int_{0}^{l} d \dot{I}(l)=j \omega \dot{E}_{k} \int_{0}^{l} Z Z(a(l)) d l= \\
=j \omega \dot{E}_{k} \int_{0}^{l} C(l)_{k i 0}^{A n} d l=j \omega \dot{E}_{k} \int_{0}^{l} C(l)_{k i 0}^{I n t} d l .
\end{array}\right\}
$$

Since there is no current in $\mathrm{Z}_{\mathrm{e} 0}$ resistance, the voltage is $\dot{U}_{\mathrm{ab}}(l)=\dot{U}_{\mathrm{A}^{\prime}}(l)$ :

$$
\dot{U}_{\mathrm{ab}}(l)=\dot{U}_{\mathrm{A}^{\prime}}(l)=\underline{Z}_{\mathrm{W} i 0} \int_{l}^{\mathrm{p}} \dot{I}(l) d l+\dot{I}(\mathrm{p}) R_{\mathrm{GD}} .
$$

Figure 9 shows $\dot{I}(l)$ current module distribution along grounded at left end $i$ line $l_{i}=\mathrm{p}=100 \mathrm{~km}$ length, calculated for $Z Z(a(l)), C(l)_{k i 0}^{I n t}$ and $C(l)_{k i 0}^{A n}$ capacities: at $a_{0}=5 \mathrm{~m}, \Delta a(\mathrm{p})=100 \mathrm{~m}$ and $\Theta=0.0573^{\circ}$ angle (a); as well as for parallel $i$ and $k$ lines at $a_{0}=5 \mathrm{~m}, \Delta a(\mathrm{p})=0 \mathrm{~m}$ and $\Theta=0^{\circ}$ angle (b).
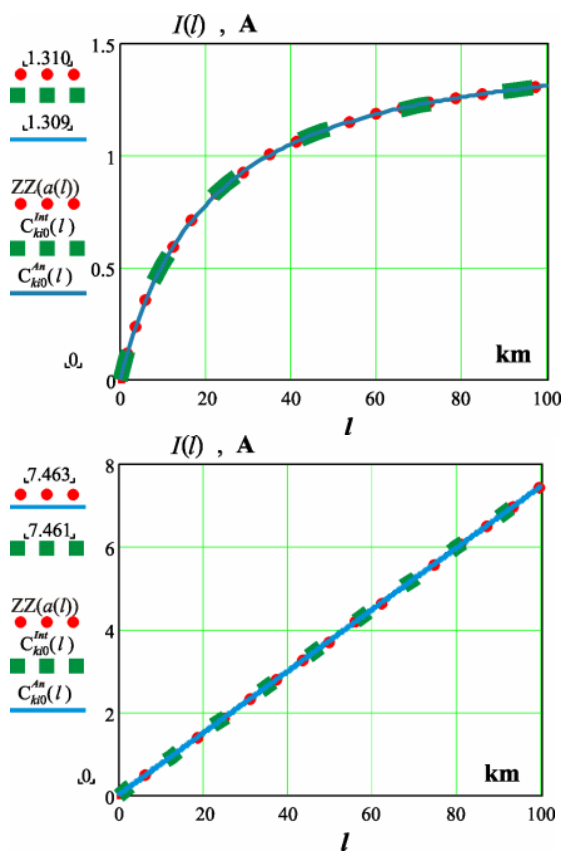

Fig. 9. Current module $\dot{I}(l)$ distribution for $Z Z(a(l))$, $C(l)_{k i 0}^{I n t}$ and $C(l)_{k i 0}^{A n}$ : (a) converging $i$ and $k$ lines at $\mathrm{p}=$ $100 \mathrm{~km}, a_{0}=5 \mathrm{~m}, \Delta a(\mathrm{p})=100 \mathrm{~m}$; (b) parallel lines at $\mathrm{p}=$ $100 \mathrm{~km}, a_{0}=5 \mathrm{~m}, \Delta a(\mathrm{p})=0 \mathrm{~m}$ 
Figure 10 shows voltages $\dot{U}_{\mathrm{A}^{\prime}}(l)=\dot{U}_{\mathrm{ab}}(l)$ modules (a) and arguments (b) distribution for $Z Z(a(l)), C(l)_{k i 0}^{I n t}$ and $C(l)_{k i 0}^{A n}$ at $a_{0}=5 \mathrm{~m}, \Delta a(\mathrm{p})=100 \mathrm{~m}, \mathrm{p}=100 \mathrm{~km}$.
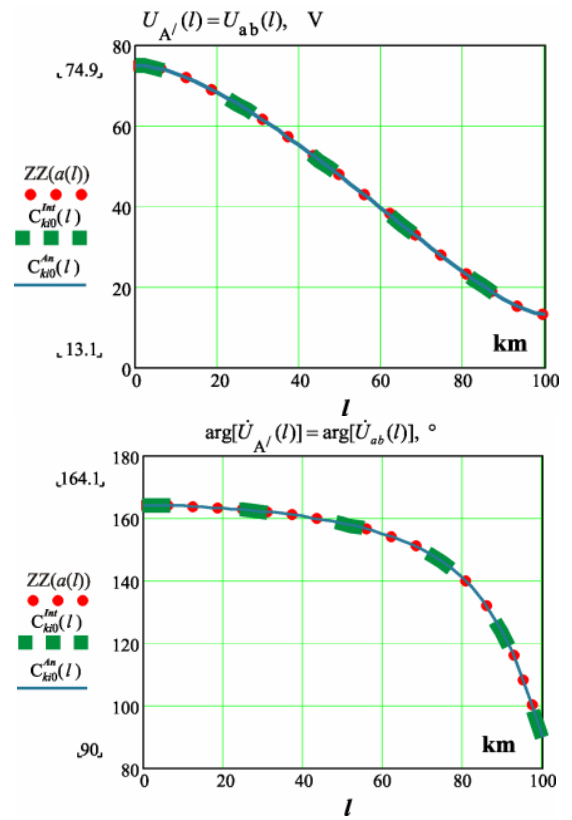

Fig. 10. Voltages $\dot{U}_{\mathrm{A}^{\prime}}(l)=\dot{U}_{\mathrm{ab}}(l)$ modules (a) and arguments (b) distribution for $Z Z(a(l)), C(l)_{k i 0}^{I n t}$ and $C(l)_{k i 0}^{A n}$ at $a_{0}=5$ $\mathrm{m}, \Delta a(\mathrm{p})=100 \mathrm{~m}, \mathrm{p}=100 \mathrm{~km}$

Voltage module $\dot{U}_{\mathrm{ab}}(l)=\dot{U}_{\mathrm{ab}}(0)$ at the ungrounded $i$ line end, when it is grounded at far from $k$ line end конце (Figure 8), exceed 2.4 times voltage module $\dot{U}_{\mathrm{ab}}(l)=\dot{U}_{\mathrm{ab}}(\mathrm{p})$ value at ungrounded $i$ line end (Figure

7a) when it is grounded at near to with $k$ line end (Figure 5). This is mathematically explained by larger area under the curve $\dot{I}(l)$ in Figure 9a, than in Figure 7a, calculated by the integral $\int \dot{I}(l) d l$, included in the expression of voltage $\dot{U}_{\mathrm{A}^{\prime}}(l)$ и $\dot{U}_{\mathrm{ab}}(l)$. The physical explanation is that in case of $i$ line grounded at far from $k$ end induced current $\dot{I}(l)$ module from the beginning to the end of $i$ line is higher than in case of $i$ line grounded at near $k$ line end.

\section{Currents and voltages of grounded at one end $i$ line depending on length $l_{i}=p$, angle of convergence $\Theta$ and minimal distance $a_{0}$ between $k$ and $i$ lines}

Consider the case of $i$ line grounding at far from $k$ line right end (Figure 8), when induced voltage in ungrounded end of $i$ line is most significant.

In expression (7) $a$ function variables will be $a_{0}, l$ and $\Theta: a\left(a_{0}, l, \Theta\right)$. Partial capacity between lines we present in analytical form: $C_{k i 0}(a)=C_{k i 0}^{A n}(a)$. Substituting $a\left(a_{0}, l, \Theta\right)$ function in expression (5) instead of variable $a$ get $C_{k i 0}^{A n}\left(a_{0}, l, \Theta\right)$. Similarly, by introducing additional variables into formulas (7) and (8), we obtain equations for current and voltage: $\dot{I}\left(a_{0}, l, \Theta\right)$ and $\dot{U}_{\mathrm{ab}}\left(a_{0}, l, \Theta\right)$.

Take the angle $\Theta=0.0573^{\circ}$. Figure 11 shows the distribution of current modules $\dot{I}\left(a_{0}, l=\mathrm{p}, \Theta\right)$ (a) and voltage modules $\dot{U}_{\mathrm{A}^{\prime}}\left(a_{0}, l=\mathrm{p}, \Theta\right)=\dot{U}_{\mathrm{ab}}\left(a_{0}, l=\mathrm{p}, \Theta\right)(\mathrm{b})$, for case of grounded $(l=\mathrm{p}) i$ line, as well as Figure 12 shows voltage $\dot{U}_{\mathrm{A}^{\prime}}\left(a_{0}, l=0, \Theta\right)=\dot{U}_{\mathrm{ab}}\left(a_{0}, l=0, \Theta\right)$ module values for case of ungrounded $(l=0) i$ line end $l_{\mathrm{i}}$ $=\mathrm{p}=100,50$ и $10 \mathrm{~km}$ length with minimum distance $a_{0}$ between $k$ and $i$ lines change from 5 to $100 \mathrm{~m}$.
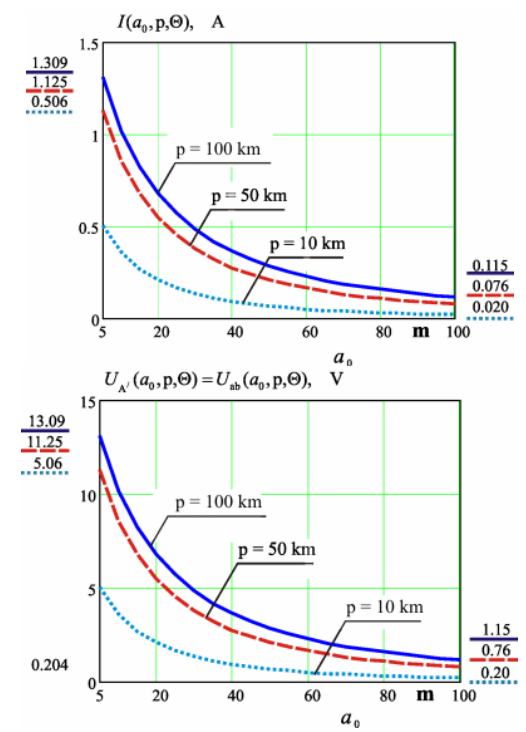

Fig. 11. Current module value $\dot{I}\left(a_{0}, \mathrm{p}, \Theta\right)$ distribution (a), voltage module value $\dot{U}_{\mathrm{A}^{\prime}}\left(a_{0}, \mathrm{p}, \Theta\right)$ distribution (b) for case of grounded $i$ line $(l=\mathrm{p})$ when $\mathrm{p}=100,50$ и $10 \mathrm{~km}$ at $a_{0}$ change from 5 to $100 \mathrm{~m}$

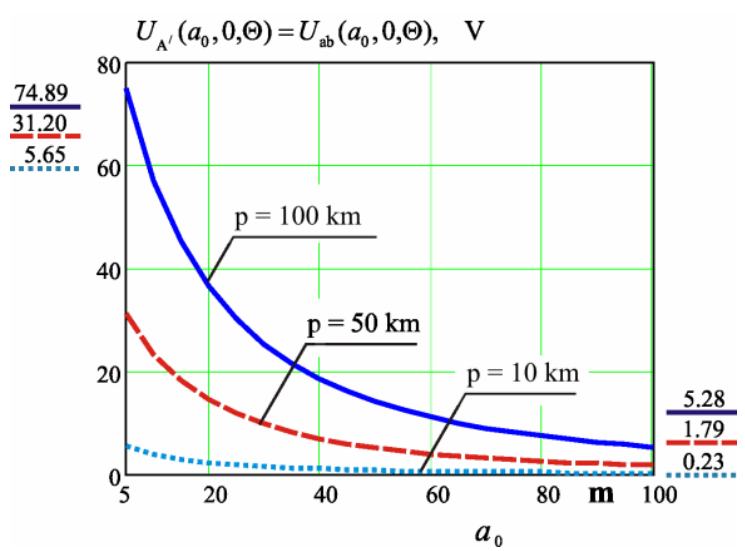

Fig. 12. Voltage module $\dot{U}_{\mathrm{A}^{\prime}}\left(a_{0}, 0, \Theta\right)$ distribution at ungrounded $i$ line $(l=0)$ end for $\mathrm{p}=100,50$ and $10 \mathrm{~km}$ by $a_{0}$ change from 5 to $100 \mathrm{~m}$

Current module values in ungrounded end as well as voltage module values at both $i$ line ends decrease rapidly for all line' $\mathrm{p}$ length values with $a_{0}$ increase.

Take the minimal distance $a_{0}=50 \mathrm{~m}$. Figure 13 shows current module values $\dot{I}\left(a_{0}=5, l=\mathrm{p}, \Theta\right)(\mathrm{a})$, and voltage module values $\dot{U}_{\mathrm{A}^{\prime}}\left(a_{0}=50, l=\mathrm{p}, \Theta\right)=\dot{U}_{\mathrm{ab}}\left(a_{0}=50, l=\mathrm{p}, \Theta\right)$ 
length grounded case with $\Theta$ angle change from $0^{\circ}$ to $1^{\circ}$. Figure 14 shows voltage module $\dot{U}_{\mathrm{A}^{\prime}}\left(a_{0}=50, l=0, \Theta\right)=\dot{U}_{\mathrm{ab}}\left(a_{0}=50, l=0, \Theta\right) \quad$ values distribution for the same $i$ line $(l=0)$ ungrounded at the end.
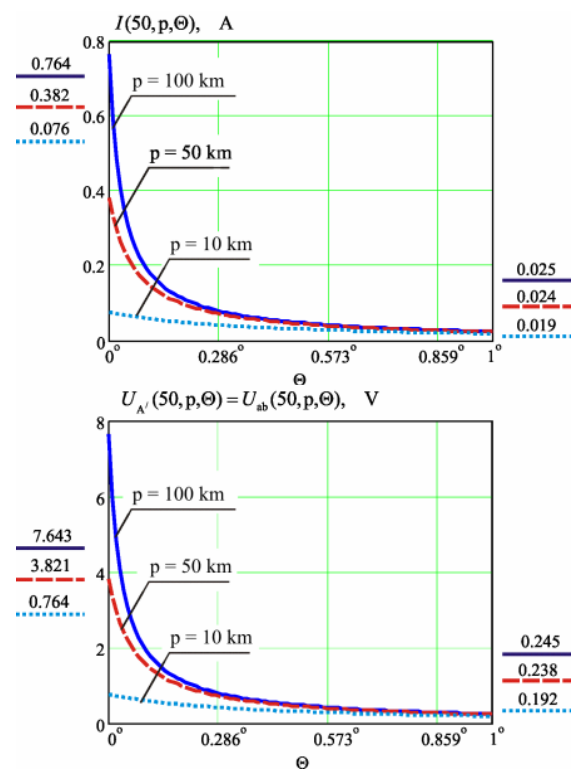

Fig. 13. Current module $\dot{I}(50, \mathrm{p}, \Theta)$ value (a); voltage module $\dot{U}_{\mathrm{A}^{\prime}}(50, \mathrm{p}, \Theta)=\dot{U}_{\mathrm{ab}}(50, \mathrm{p}, \Theta)(\mathrm{b})$, distribution for $i$ line $\left(l_{\mathrm{i}}=\right.$ p) $l_{\mathrm{i}}=\mathrm{p}=100,50$ and $10 \mathrm{~km}$ length grounded case with $\Theta$ angle change from $0^{\circ}$ to $1^{\circ}$

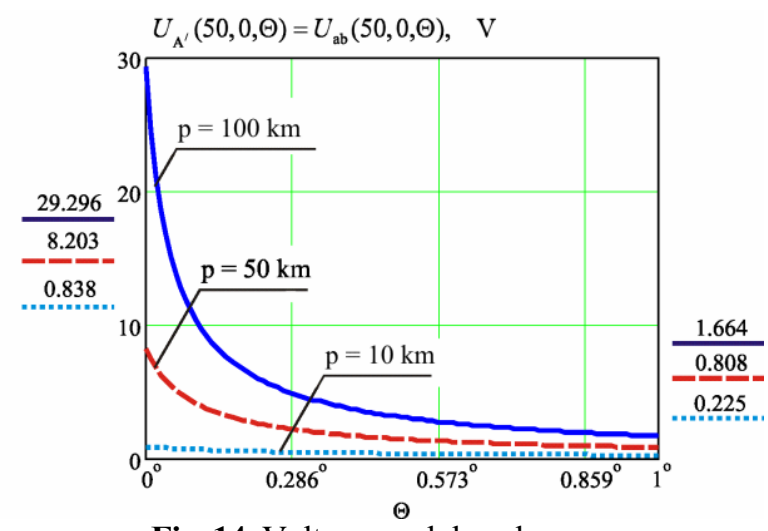

Fig. 14. Voltage module values

$\dot{U}_{\mathrm{A}^{\prime}}(50,0, \Theta)=\dot{U}_{\mathrm{ab}}(50,0, \Theta)$ distribution at ungrounded end of $i$ line $(l=0)$ with $l_{\mathrm{i}}=\mathrm{p}=100,50$ and $10 \mathrm{~km}$ length under $a_{0}=50 \mathrm{~m}$ and $\Theta$ angle change from $0^{\circ}$ to $1^{\circ}$

Angle $\Theta$ increase from $0^{\circ}$ to $1^{\circ}$ at $a_{0}=50 \mathrm{~m}$ leads to the same sharp decrease in current module values $\dot{I}(50, \mathrm{p}, \Theta)$, and in voltage module values $\dot{U}_{\mathrm{A}^{\prime}}(50, \mathrm{p}, \Theta)=\dot{U}_{\mathrm{ab}}(50, \mathrm{p}, \Theta)$ in grounded $i$ line end: for $\mathrm{p}=100 \mathrm{~km}$ by 31 times, for $\mathrm{p}=50 \mathrm{~km}$ by 16 times, and for $\mathrm{p}=10 \mathrm{~km}$ by 4 times. Voltage module values $\dot{U}_{\mathrm{A}^{\prime}}(50,0, \Theta)=\dot{U}_{\mathrm{ab}}(50,0, \Theta)$ at $i$ line ungrounded left end reduced by less: for $\mathrm{p}=100 \mathrm{~km}$ by 17.6 times, for $\mathrm{p}$ $=50 \mathrm{~km}$ by 10.2 times and for $\mathrm{p}=10 \mathrm{~km}$ by 3.7 times.

Current and value changes curve have are similar but more expressed for the same conditions and minimal distance $a_{0}=5 \mathrm{~m}$ (Figures 15 and 16).

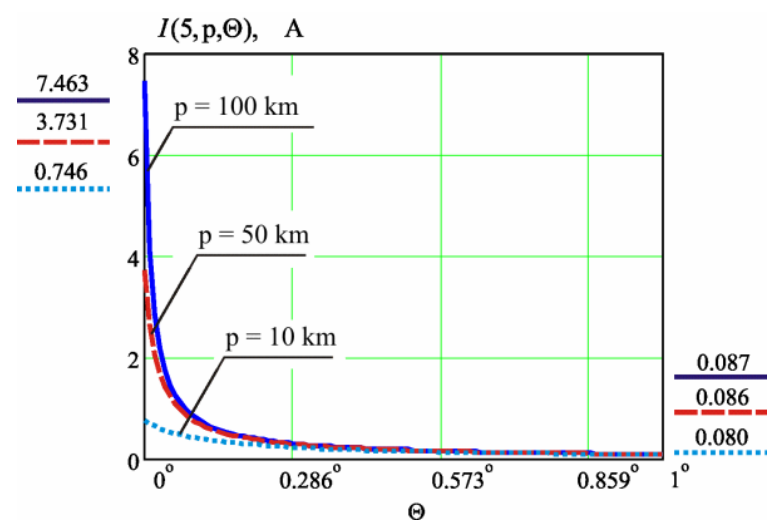

Fig. 15. Current module $\dot{I}(5, \mathrm{p}, \Theta)$ distribution in grounded end $(l=\mathrm{p})$ of $i$ line with $l_{\mathrm{i}}=\mathrm{p}=100,50$ и 10 $\mathrm{km}$ under при $a_{0}=5 \mathrm{~m}$ and $\Theta$ angle change from $0^{\circ}$ to $1^{\circ}$
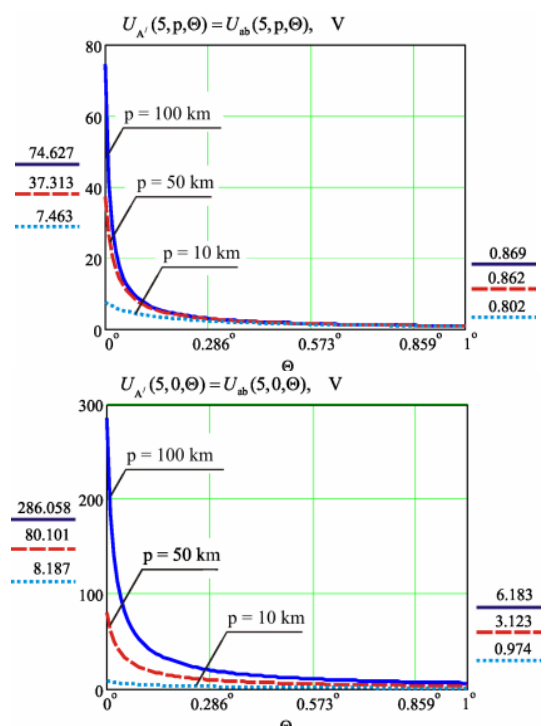

Fig. 16. . Voltage module values

$\dot{U}_{\mathrm{A}^{\prime}}(5, \mathrm{p}, \Theta)=\dot{U}_{\mathrm{ab}}(5, \mathrm{p}, \Theta)$ distribution at the ends of $i$ line with length $l_{\mathrm{i}}=\mathrm{p}=100,50$ and $10 \mathrm{~km}$ under $a_{0}=5 \mathrm{~m}$ and $\Theta$ angle change from $0^{\circ}$ to $1^{\circ}$ : (a) grounded $(l=\mathrm{p})$ and

$\dot{U}_{\mathrm{A}^{\prime}}(5,0, \Theta)=\dot{U}_{\mathrm{ab}}(5,0, \Theta)$ line end; (b) ungrounded $(l=0)$

$\Theta$ angle increase from $0^{\circ}$ to $1^{\circ}$ under $a_{0}=5 \mathrm{~m}$ leads to the same sharp decrease the values of current module $\dot{I}(5, \mathrm{p}, \Theta)$ and voltage module $\dot{U}_{\mathrm{A}^{\prime}}(50, \mathrm{p}, \Theta)=\dot{U}_{\mathrm{ab}}(5, \mathrm{p}, \Theta)$ of $i$ line grounded end: for $\mathrm{p}$ $=100 \mathrm{~km}$ by 85.8 times, for $\mathrm{p}=50 \mathrm{~km}$ by 43.3 times and for $p=10$ км by 9.3 times.

Herewith voltage module $\dot{U}_{\mathrm{A}^{\prime}}(5,0, \Theta)=\dot{U}_{\mathrm{ab}}(5,0, \Theta)$ values at ungrounded left end of $i$ line reduce by less: for $\mathrm{p}=100 \mathrm{~km}$ by 46.3 times, for $\mathrm{p}=50 \mathrm{~km}$ by 25.6 times and for $\mathrm{p}=10 \mathrm{~km}$ by 8.4 times.

\section{Conclusion}

Calculation results synthesis shows that for partial capacity values between phases and cables of converging under voltage and unconnected three-phase lines determination $C_{\mathrm{ki} 0}(a)$ calculation must be carrying out taking into account the phases and cables of all, both converging and parallel lines of the considered part. 
Transfer from single-phase to three-phase designs, both under voltage and unconnected OTL leads to $C_{\text {kio }}(a)$ capacity value decrease from $1.87 \cdot 10^{-12} \mathrm{~F} / \mathrm{m}$ (Table 1 ) to $1.43 \cdot 10^{-12} \mathrm{~F} / \mathrm{m}$ under $\mathrm{H}=19 \mathrm{~m}, \mathrm{~h}=17.5 \mathrm{~m}$ and $a=5 \mathrm{~m}$, that in result leads to induced current and voltage values in disconnected line decrease.

Given algorithms with superposition method use allow to determine the values of converging three-phase OTL induced voltage that lead to personnel' work reliability and safety elevation.

$U_{\mathrm{ab}}$ transverse voltage induced in $i$ unconnected line by electric field of converging with it $k$ line under voltage can be neglected in case of violation from the values of any tested parameters presented in table 2 as well as in [7]: the length of $i$ line converging part $l_{i}=\mathrm{p}$, minimal distance $a_{0}$ between converging lines, convergence angle $\Theta$.

Table 2. Tested parameters values

\begin{tabular}{|c|c|}
\hline $\begin{array}{l}\text { Parameter value for } \\
U_{\mathrm{ab}} \text { voltage } \\
\text { possibility of neglect }\end{array}$ & $\begin{array}{c}U_{\mathrm{ab}} \text { voltage as well as another } \\
\text { parameters }\end{array}$ \\
\hline $\begin{array}{c}\text { - The length of } i \text { line } \\
\text { converging part } \\
l_{i}=\mathrm{p}<1 \mathrm{~km}\end{array}$ & $\begin{array}{l}\dot{U}_{\mathrm{A}^{\prime}} \approx 2 \mathrm{~V} \text { at ungrounded end, } \\
\text { even under } a_{0}=5 \mathrm{~m} \text { and } \\
\text { converging angle } \Theta= \\
0.0573^{\circ} \text { (Figure } 12 \text { ) }\end{array}$ \\
\hline $\begin{array}{l}\text { - Minimal distance } \\
\text { between converging } \\
\text { lines } a_{0} \geq 100 \mathrm{~m}\end{array}$ & $\begin{array}{l}\text { Highest voltage value } \dot{U}_{\mathrm{A}^{\prime}}= \\
5.3 \mathrm{~V} \text { at ungrounded end, even } \\
\text { under } l_{i}=\mathrm{p}=100 \mathrm{~km} \text { and } \\
\text { converging angle } \Theta=0.0573^{\circ} \\
\text { (Figure 12) }\end{array}$ \\
\hline $\begin{array}{l}\text { - Converging angle } \\
\Theta \geq 5^{\circ} \text { (with reserve) }\end{array}$ & $\begin{array}{l}\dot{U}_{\mathrm{A}^{\prime}}=6.2 \mathrm{~V} \\
\text { ungrounded at } \\
\text { under } a_{0}=5 \mathrm{~m}, l_{i}=\mathrm{p}= \\
100 \mathrm{~km} \text { and } \Theta=1^{\circ} \text { (Figure } \\
16 \mathrm{~b} \text { ) }\end{array}$ \\
\hline
\end{tabular}

\section{Reference}

1. Korovkin N.V., Selina E.E., Chechurin V.L. Theoretical foundations of electrical engineering. - S-Pb.: Piter, 2006. - 512 p. (in Russian)

2. Neiman L.R., Demirchjan K.S. Theoretical foundations of electrical engineering. V.2. - L.: Power. 1967. - 408 p. (in Russian).

3. Misrikhanov M.Sh., Iostson Yu.A., Rubtsova N.B., Tokarskiy A.Yu. Computer program "Electromagnetic parameters of overhead transmission lines № 2006613744, 27.10.2006 (in Russian).

4. Kostenko M.V., Perelman L.S., Shkarin Yu.P. Wave processes and electrical disturbances in multi-wire high-voltage lines. Energy. M., 1973.- 272 p. (in Russian)

5. Tsitsikjan G.N. Electromagnetic compatibility in power industry. St-Petersburg, ELMOR., 2007- 184 p. (in Russian)

6. Guidelines for the calculation of short-circuit currents and the selection of electrical equipment. G153-34.0-20.527-98. Energia. M, (1998). - 83 p. (in Russian)

7. A.Yu. Tokarskiy, N.B.Rubtsova Distribution of voltage induced by parallel transmission line along dead and grounded line. Safety in the Technosphere, 2015, 4 (June-July), 32-38 (in Russian) 